\title{
Response Anticipation and Response Conflict: An Event-Related Potential and Functional Magnetic Resonance Imaging Study
}

\author{
Jin Fan, ${ }^{1,2}$ Rachel Kolster, ${ }^{3,5}$ Jamshid Ghajar, ${ }^{3,4}$ Minah Suh, ${ }^{4}$ Robert T. Knight, ${ }^{6}$ Ranjeeta Sarkar, ${ }^{3}$ and \\ Bruce D. McCandliss 5 \\ Departments of ${ }^{1}$ Psychiatry and ${ }^{2}$ Neuroscience, Mount Sinai School of Medicine, New York, New York 10029, ${ }^{3}$ Brain Trauma Foundation, New York, New \\ York 10017, ${ }^{4}$ Department of Neurological Surgery and ${ }^{5}$ Sackler Institute for Developmental Psychobiology, Weill Medical College of Cornell University, New \\ York, New York 10021, and 'Department of Psychology and the Helen Wills Neuroscience Institute, University of California at Berkeley, Berkeley, California \\ 94720
}

Response anticipation and response conflict processes are supported by executive control. However, few neuroimaging studies have attempted to study the relationship between these two processes in the same experimental session. In this study, we isolated brain activity associated with response anticipation (after a cue to prepare vs relax) and with response conflict (responding to a target with incongruent vs congruent flankers) and examined the independence and interaction of brain networks supporting these processes using event-related potentials (ERPs) and functional magnetic resonance imaging. Response anticipation generated a contingent negative variation ERP that correlated with shorter reaction times, and was associated with activation of a thalamo-cortico-striatal network, as well as increased gamma band power in frontal and parietal regions, and decreased spectral power in theta, alpha, and beta bands in most regions. Response conflict was associated with increased activation in the anterior cingulate cortex (ACC) and prefrontal cortex of the executive control network, with an overlap in activation with response anticipation in regions including the middle frontal gyrus, ACC, and superior parietal lobule. Although the executive control network showed increased activation in response to unanticipated versus anticipated targets, the response conflict effect was not altered by response anticipation. These results suggest that common regions of a dorsal frontoparietal network and the ACC are engaged in the flexible control of a wide range of executive processes, and that response anticipation modulates overall activity in the executive control network but does not interact with response conflict processing.

Key words: response anticipation; response conflict; executive control; ERP; fMRI; gamma

\section{Introduction}

Reaction times improve after a warning signal that leads to anticipation of the target response, which is reflected in a cholinergic dependent long-latency negative polarity event-related potential (ERP) called the contingent negative variation (CNV) (Walter et al., 1964). Numerous studies (Tecce, 1972; Lang et al., 1988; Alexander and Crutcher, 1990; Ulrich et al., 1998; Lee et al., 1999; Leuthold and Jentzsch, 2001; Isomura et al., 2003; Paradiso et al., 2004) suggest that anticipatory attention, motivation, and motor preparation are indexed by the CNV. The parallel activation patterns observed between the CNV (Birbaumer et al., 1990; Brunia, 1999; Brunia and van Boxtel, 2001) and neurons in the prefrontal cortex (PFC) (Fuster, 1990; Rockstroh et al., 1993; Rosahl and

Received Aug. 10, 2006; revised Jan. 18, 2007; accepted Jan. 25, 2007.

This work was supported by National Science Foundation Grant NSF-REC-0337715 (B.D.M.) and National Institutes of Health Grant R01DC007694 (B.D.M.). The Cognitive and Neurobiological Research Consortium in Traumatic Brain Injury research is supported by the James $S$. McDonnell Foundation through a collaborative grant to the Brain Trauma Foundation.

Correspondence should be addressed to Dr. Jin Fan, Department of Psychiatry, Mount Sinai School of Medicine, One Gustave L. Levy Place, Box 1230, New York, NY 10029. E-mail: Jin.Fan@mssm.edu. D0I:10.1523/JNEUROSCI.3470-06.2007

Copyright $\odot 2007$ Society for Neuroscience $\quad$ 0270-6474/07/272272-11\$15.00/0
Knight, 1995), posterior parietal cortex (Durstewitz, 2004), and thalamus (Komura et al., 2001) indicate that the CNV measures neuronal activity within a thalamo-cortical-striatal network (Ikeda et al., 1997; Macar and Vidal, 2003; Pfeuty et al., 2005).

A central component of response anticipation is achieving and maintaining an alert state (Bertelson, 1967). Response anticipation has also been shown to include top-down processes of attention, which typically engage prefrontal and parietal cortices (Corbetta and Shulman, 2002; Liang et al., 2002; Foxe et al., 2005; Badler and Heinen, 2006). These top-down control processes may be related to other executive functions, such as those recruited during response conflict (Gruber and Goschke, 2004). There is evidence that these two processes share some common neural structures. For instance, response anticipation has been shown to engage the anterior cingulate cortex (ACC) and PFC (Frith et al., 1991; Dagher et al., 1999; Quintana et al., 2004; Fassbender et al., 2006), regions that have been implicated in the executive control functions of conflict monitoring and resolution (Bush et al., 2000; MacDonald et al., 2000; Fan et al., 2003), as well as cued task-set implementation and maintenance (Dosenbach et al., 2006).

Although both alerting and the presence of conflict have been 
shown to influence reaction times when both are measured in the same task, such as in the attention network test, no significant correlation between alerting and response conflict effects was observed (Fan et al., 2002, 2005). The lack of correlation between alerting and response conflict effects even in the presence of some overlap in the anatomy of the two processes makes it important to examine both the functional independence as well as interactivity of the networks involved in response anticipation and response conflict. To address this issue, we examined brain activity associated with these processes in an event-related paradigm designed to elicit the $\mathrm{CNV}$ and response conflict. Importantly, we used both ERPs and functional magnetic resonance imaging (fMRI) to track the underlying spatiotemporal activity supporting both processes. We predicted that brain networks having both common and process-dependent structures would be involved in response anticipation and response conflict processes, and that response anticipation would modulate but not interact with response conflict.

\section{Materials and Methods}

Participants. Nineteen healthy adults ( 9 females) participated in ERP recordings (mean age, 26 years; range, 18-59 years), and 20 healthy adults ( 9 females) participated in fMRI scanning (mean age, 26 years; range, $18-59$ years). Eighteen subjects participated in both ERP recordings and fMRI scanning. Exclusion criteria for participation were previous traumatic brain injury with loss of consciousness within the past year, pregnancy, acute intoxication, drug or alcohol abuse history, neurological or psychiatric diagnosis, seizure disorder, and all constraining factors for MRI, such as claustrophobia. A signed informed consent approved by the New York Presbyterian Hospital/Weill Medical College of Cornell University was obtained from each participant before the experiment. Participants were reimbursed for participation in the study.

Task design. In each trial, a warning cue period was followed by an imperative target period after a cue-target interval. See Figure 1 for a schematic of the response anticipation-response conflict paradigm. There were two cue conditions: no-cue and cue, with the cue condition subdivided into relax and ready cues. In addition, there were two target conditions: no-target and target, with the target condition subdivided into targets with congruent and incongruent flankers. This resulted in four trial types: (1) no cue, no target (baseline), (2) no cue, target (congruent or incongruent), (3) relax cue, no target, and (4) ready cue, target (congruent or incongruent). In the no-cue-no-target trials, participants were shown no events but only the consistent appearance of a fixation cross. In the no-cue-target trials, there was an unexpected target presentation. In the relax cue trials, participants were shown a pair of triangles above and below fixation, indicating that no target or flankers would be presented. In the ready cue trials, participants were shown a pair of circles above and below fixation, informing participants to get ready to respond to the upcoming target. The target was an arrow flanked on both sides by either two arrows in the same direction (congruent condition) or in the opposite direction (incongruent condition). The cues and targets were black with a gray screen background. The visual angle parameters for the target and flankers have been described previously (Fan et al., 2002, 2003). The time course was $250 \mathrm{~ms}$ for the cue period, $2250 \mathrm{~ms}$ for the cue-target interval, $250 \mathrm{~ms}$ for the target period, $2000 \mathrm{~ms}$ for the response window, and $3000 \mathrm{~ms}$, plus a jittered interval between 0 and $500 \mathrm{~ms}$ with a mean of $250 \mathrm{~ms}$, for the intertrial interval. The average trial duration was $8 \mathrm{~s}$.

Participants indicated the direction of the center arrow by pressing one key with the left hand for the left direction and another key with the right hand for the right direction. The 16 trial combinations of 2 (no cue, cue) $\times 2$ (no target, target $) \times 2$ (congruent, incongruent flankers $) \times 2$ (left, right hand response) were psuedorandomized across the 8 runs of 32 trials so that each trial type had an equal probability of appearing before and after each specific trial. Each run lasted $288 \mathrm{~s}$. The first and last $16 \mathrm{~s}$ of each run were rest periods. Reaction time (RT) and accuracy were recorded for each trial. Stimulus presentation and behavioral response
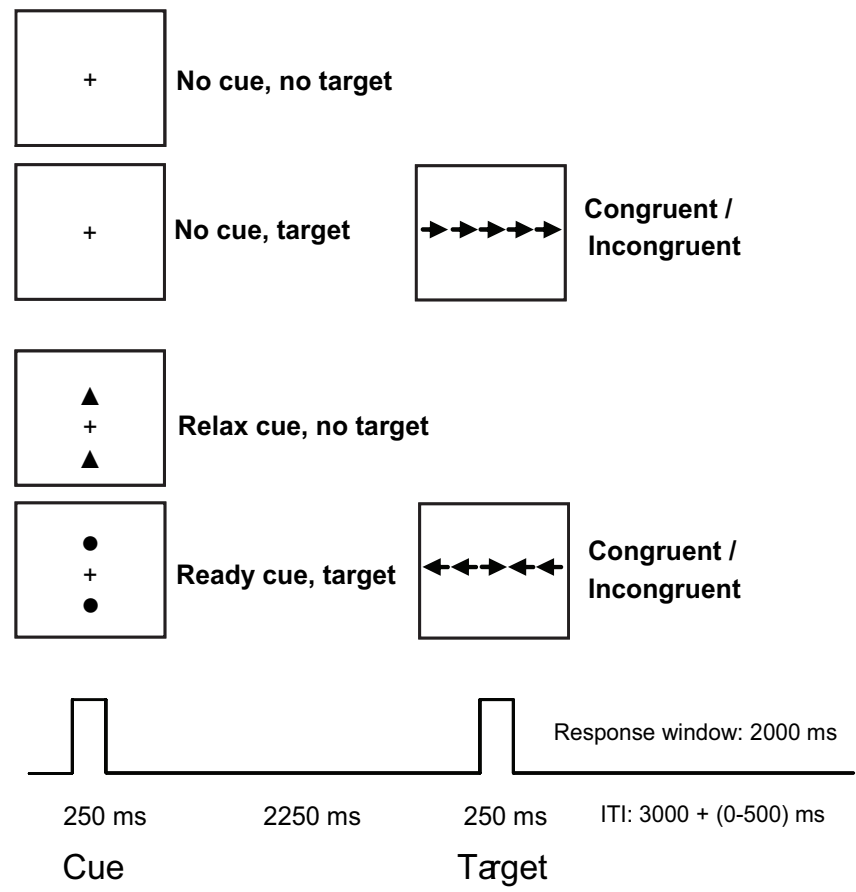

Figure 1. Schematic of the task for eliciting response anticipation and response conflict. In each trial, a $250 \mathrm{~ms}$ cue period was followed by an imperative $250 \mathrm{~ms}$ target stimulus (the center arrow in a row of 5 arrows), with a 2250 ms cue-target interval and a 2000 ms response window. The intertrial interval was jittered between 3000 and $3500 \mathrm{~ms}$ with an average duration of $3250 \mathrm{~ms}$. There were two cue conditions: uncued trials and cued trials, including relax and ready cues. There were two target conditions: targets with congruent or incongruent flankers. The participants' task was to indicate the direction of the target.

collection were performed with E-Prime (Psychology Software Tools, Pittsburgh, PA).

ERP data acquisition. ERP data were recorded using a 128-channel Geodesic Sensor Net (Tucker, 1993) and the Geodesic EEG System (Electrical Geodesics, Eugene, OR) with a $0.1-100 \mathrm{~Hz}$ bandpass filter and a sampling rate of 250 samples per second digitized with a 12 bit A/D converter. The impedance of all electrodes was $<40 \mathrm{~K} \Omega$ at the start time, with the exception of electrodes marked as unusable. Recordings in every channel were referenced to $\mathrm{Cz}$ during acquisition, and then averagereferenced off-line. The experimental control personal computer running E-Prime was synchronized to and communicated with the EEG system. The trial events, including the cue and target type and onset/ offset time, were sent to the data recording system via a standard serial port to record, together with the ERP data. ERPs were recorded for all of the eight runs of trials.

fMRI data acquisition. Participants were scanned with a General Electric Signa 3.0 tesla MRI scanner (General Electric Medical Systems, Milwaukee, WI). A spiral in-and-out sequence (Glover and Thomason, 2004) was used to collect functional blood oxygen level-dependent (BOLD) signal. The parameters used were as follows: repetition time, $2500 \mathrm{~ms}$; echo time, $40 \mathrm{~ms}$; field of view (FOV), $220 \mathrm{~mm}$; flip angle, $90^{\circ}$; $64 \times 64$ matrix; 32 of 5 -mm-thick (skip $0 \mathrm{~mm}$ ) axial slices with an in-plane resolution of $3.4375 \times 3.4375 \mathrm{~mm}$, parallel with anterior commissure-posterior commissure. The total volume number for each run was 116 . In-plane T1-weighted anatomic images $(256 \times 256$ in-plane resolution) were acquired with the same prescription as the functional images. A whole-brain, high-resolution, T1-weighted anatomic scan (three-dimensional spoiled gradient; $256 \times 256$ in-plane resolution; 240 $\mathrm{mm}$ FOV; $124 \times 1.5 \mathrm{~mm}$ axial slices) was also acquired for each participant. For fMRI, the first run was used as a practice run, and both the first run and the last (eighth) run were not scanned because of technical limitations.

Behavioral data analysis. Mean reaction times of correct responses and accuracy of responses were submitted to a general linear model (GLM) of 
repeated measures with the two factors of cue (cued, uncued) by target (congruent, incongruent) for the target response. This provided a metric of the degree to which top-down control processes of response anticipation exerted an influence on reaction times (i.e., cue main effect), the degree to which conflict processing influenced reaction times (i.e., conflict main effect), and potential interactions between response anticipation and response conflict processes. All data were collapsed over left and right response hands.

ERP data analysis. ERP data were segmented by correct and incorrect responses separately, with a time window of $200 \mathrm{~ms}$ before to $3000 \mathrm{~ms}$ after the cue onset for the cue-locked ERP, $200 \mathrm{~ms}$ before to $800 \mathrm{~ms}$ after the target onset for the target-locked ERP, and $400 \mathrm{~ms}$ before to $400 \mathrm{~ms}$ after the response for the response-locked ERP. Segments with incorrect responses were excluded from additional data analysis. Cue-locked segments consisted of four types of segments: no-cue-no-target, no-cuetarget, relax-cue-no-target, and ready-cue-target. Target and response locked segments also consisted of four types of segments: no-cue-targetcongruent, cue-target-congruent, no-cue-target-incongruent, cuetarget-incongruent. A channel was interpolated using the spherical splines method if $>20 \%$ of the segments were unusable. The maximum number of unusable channels for each participant was 10. Artifact rejection was performed over the entire epoch using a moving window method with a transit threshold of $50 \mu \mathrm{V}$ and voltage threshold of 100 $\mu \mathrm{V}$. Eye blinks and horizontal eye movements were defined as 50 and 30 $\mu \mathrm{V}$, respectively. The above steps were performed using the Net Station software (Electrical Geodesics).

Subsequently, averaging was performed using BESA 5.1 software (MEGIS Software, Munich, Germany) on each type of segment from individual participants. Artifact rejection was performed again over all segments with an amplitude threshold of $160 \mu \mathrm{V}$ and gradient of 75 $\mu \mathrm{V} /$ sample, defined as amplitude change from one sample to the next. Participants with $<10 \%$ of trials accepted in any condition were excluded from ERP analysis (with the exception of one participant, who had $3 \%$ of trials accepted in the ready cue condition), resulting in three participants being excluded from cue-locked analysis, seven from targetlocked analysis, and five from the response locked analysis. Regression of the CNV amplitude on the number of accepted trials for the ready and relax cue conditions was performed to test whether there was a significant relationship between the $\mathrm{CNV}$ amplitude and the accepted trial number. The nonsignificant regression results assured that differences in overall signal-to-noise ratios (i.e., the number of trials accepted) were not a factor in CNV amplitude. The epoch for the cue-locked ERP was 3200 $\mathrm{ms}$, with a $200 \mathrm{~ms}$ baseline and a $3000 \mathrm{~ms}$ period after the onset of the cue. The epoch for the target-locked ERP was $1000 \mathrm{~ms}$, with a $200 \mathrm{~ms}$ baseline and an $800 \mathrm{~ms}$ period after the onset of the target. The epoch for the response-locked ERP was $800 \mathrm{~ms}$, with $400 \mathrm{~ms}$ before and $400 \mathrm{~ms}$ after the response. The high-pass filter was set to $0.1 \mathrm{~Hz}$, with a $6 \mathrm{db} /$ oct slope and zero phase. Grand averages were made separately for each condition of cue-locked $(n=16)$, target-locked $(n=12)$, and response-locked ( $n=14)$ using averaged data from individual participants, and a lowpass filter of $15 \mathrm{~Hz}$ was applied. To investigate the CNV related to response anticipation, the waveforms of the E6 electrode, located close to $\mathrm{Fz}$ (see Fig. 3B), and the six surrounding electrodes (E5, E7, E12, E13, E107, E113) over the interval from 600 to $1000 \mathrm{~ms}$ after cue onset were averaged and compared between the ready-cue-target and relax-cue-notarget conditions in the averaged data of individual participants. To investigate the conflict-related ERP, the means of peak amplitude and latency to peak of P1, N2, and P3 were compared across the following 2 cue $\times 2$ target conditions: ready-cue-congruent, ready-cue-incongruent, no-cue-congruent, and no-cue-incongruent.

fMRI data analysis. fMRI data analysis was conducted on both cueand target-related activation as well as on the influence of response anticipation and conflict conditions on activation in the executive control network. Event-related analysis of the fMRI data was conducted using statistical parametric mapping (SPM2; Wellcome Department of Imaging Neuroscience, London, UK). The first two volumes of each run were discarded. The functional scans were realigned to the first volume of the remaining 114 volumes, coregistered to the T1 image, normalized to a standard template [Montreal Neurological Institute (MNI)], and spa-
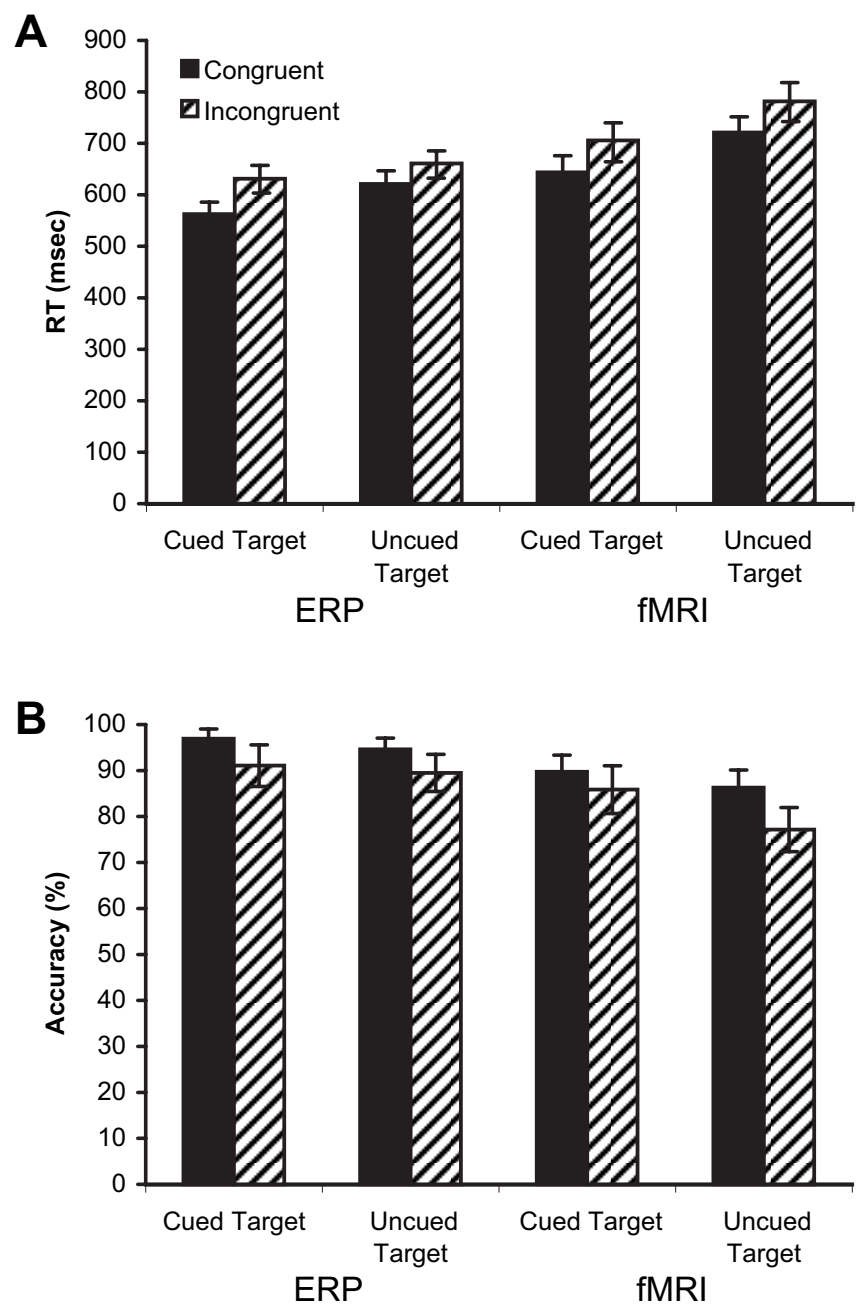

Figure 2. $\quad A, B$, Behavioral results corresponding to cue and target conditions during ERP recording and fMRI scanning for RT $(\boldsymbol{A})$ and accuracy $(\boldsymbol{B})$. For responses to cued versus uncued targets, RTs were shorter during both ERP and fMRI testing, and accuracy was greater during fMRI testing. In addition, RTs were longer and accuracy was reduced for responses to incongruent versus congruent targets. There was no significant interaction between cue and target conditions. Error bars represent \pm 1 SEM.

tially smoothed with an $8 \times 8 \times 8 \mathrm{~mm}$ full-width at half-maximum (FWHM) Gaussian kernel. GLM was conducted for the functional scans from each participant by modeling the observed event-related BOLD signal and regressors to identify the relationship between the BOLD signal and the regressors. Regressors were created by convolving a train of $\delta$ functions representing the cue and target events with the default SPM basis function, which consists of a synthetic hemodynamic response function composed of two gamma functions and its derivative (Friston et al., 1998). There were two cue-related regressors: relax cue and ready cue, and eight target-related regressors: 2 (flanker congruency: congruent and incongruent $) \times 2$ (target direction: left and right) $\times 2$ (cue condition: uncued and cued). The six parameters ( $x, y$, and $z$ translations and rotations) generated during motion correction were entered as covariates of no interest in the first-level GLM, because it has been suggested that inclusion of these covariates is generally useful for increasing the sensitivity of GLM in the analysis of event-related fMRI (Johnstone et al., 2006). The specific effects of the cue and target, including their interactions, were tested by applying appropriate linear contrasts to the parameter estimates resulting in contrast maps for each participant for cue types, target types, and interaction effects. The data were collapsed over target direction (and therefore response hand).

The images of contrast estimates of all participants were entered into a second-level group analysis conducted with a random-effects statistical 

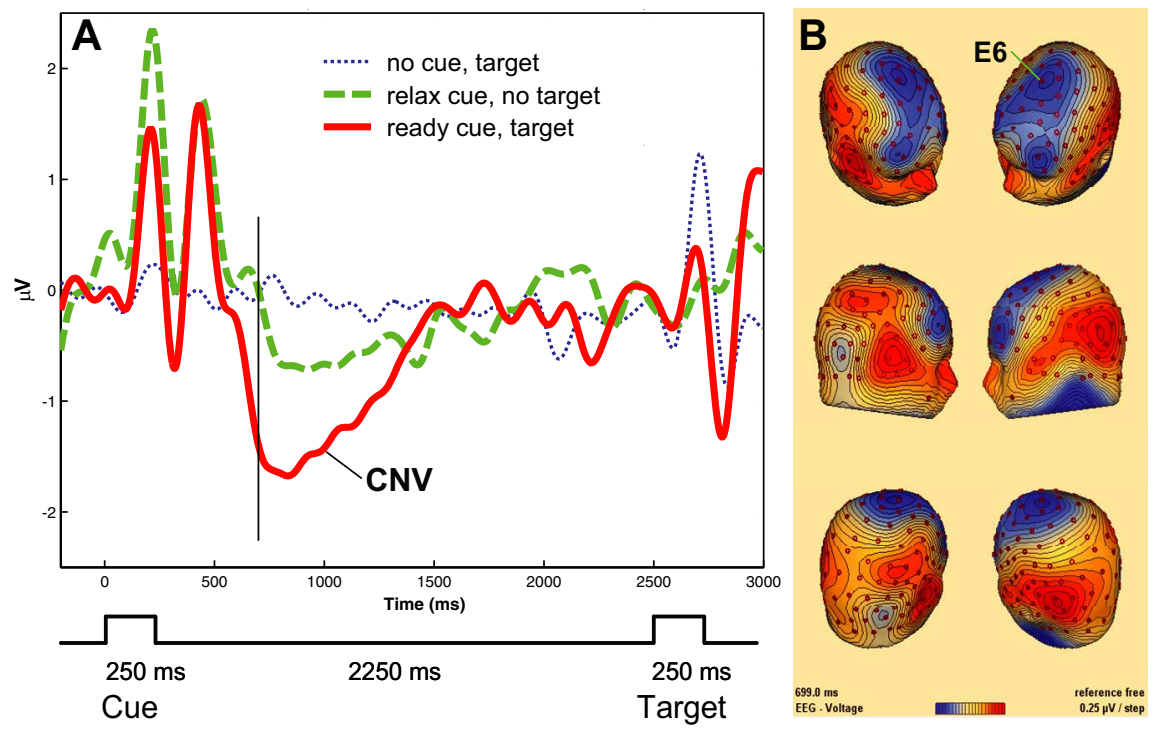

Figure 3. $A$, ERP waveforms as a function of cue type. The ERP amplitude was greater in the ready cue than in the relax cue condition at $\sim 700 \mathrm{~ms}$ after the cue onset. $\boldsymbol{B}$, Scalp topography of the voltage difference of ready cue minus relax cue at $699 \mathrm{~ms}$. The time point corresponds to the vertical line in $\boldsymbol{A}$. E6 indicates the location of the electrode with the maximum CNV amplitude.

model that accounts for intersubject variability and permits populationbased inferences. The resultant voxel-wise statistical maps were thresholded for significance using a cluster-size algorithm that protects against an inflation of the false-positive rate. An uncorrected $p$ value of 0.01 for the height (intensity) threshold of each activated voxel was used. A Monte Carlo simulation of the brain volume of the current study was conducted to establish an appropriate voxel contiguity threshold (Slotnick and Schacter, 2004). Assuming an individual voxel type I error of $p<0.01$, a cluster extent of 85 contiguous resampled voxels $(2 \times 2 \times 2$ $\mathrm{mm}^{3}$ ) was indicated as necessary to correct for multiple voxel comparisons at $p<0.05$. To calculate the RT-BOLD correlations, volumes of interest were extracted from the activated region with a radius of $6 \mathrm{~mm}$ centered at the local maximum of the mass. Finally, for the dipole modeling, the coordinates of activation in MNI space were transferred to Talairach (Talairach and Tournoux, 1988) space using a nonlinear transformation (http://www.mrc-cbu.cam.ac.uk/Imaging/mnispace.html).

We also examined all of the areas in which there was evidence of a conjunction between activation in the response anticipation and in the response conflict processes, using a conjunction analysis of SPM testing global null using the minimum $T$ statistic (Friston et al., 2005), with a global false-positive rate of 0.01 for the height threshold. This conjunction analysis makes the inference that the consistent effects are significant, but not that the significant effects are consistent (Friston et al., 2005).

Dipole modeling and power spectrum analysis of ERP data. A source model for the ERP associated with response anticipation was constructed in BESA using the cue-locked grand average with dipole locations based on the coordinates of the fMRI regions activated in the ready versus relax cue contrast. The caudate and putamen regions were excluded as these regions do not contribute to the scalp ERP because of the lack of layered neuronal organization (Crottaz-Herbette and Menon, 2006). This resulted in nine dipoles. The dipole locations were constrained and orientations were free for the model fitting. The difference waveform of the cue-locked ERP between the ready and relax cue conditions, calculated from the grand averaged data of all participants, was used for the model fitting, with a time period of $0-2500 \mathrm{~ms}$ after cue onset. To avoid fitting with bias, all of the dipole orientations were fitted simultaneously without any additional selection to link an ERP component to a specific dipole at a certain time period. Average surface points of the Geodesic Sensor Net provided by BESA were used.

The BESA source model solution generated from the grand averaged ERP was applied as a montage to the individual participants' cue-locked epochs, and power spectrum analyses were performed in BESA separately for the relax cue and ready cue conditions. Power spectral density was computed for each single trial, and then averaged across trials for each participant in each condition. The time-frequency sampling was $2 \mathrm{~Hz} / 25 \mathrm{~ms}$. BESA uses a complex demodulation to transform time-domain data into the time-frequency domain (Papp and Ktonas, 1977). This complex demodulation consists of a multiplication of the time-domain signal with a complex periodic exponential function, with a frequency equal to the frequency under analysis, and a subsequent low-pass filter. This lowpass filter is a FIR filter of Gaussian shape in the time domain, which is related to the envelope of the moving window in wavelet analysis. For our setting of a $2 \mathrm{~Hz} / 25 \mathrm{~ms}$ time-frequency sampling, this filter has a width of $5.7 \mathrm{~Hz}$ in frequency domain and $79 \mathrm{~ms}$ in the time domain of FWHM. For additional details about the BESA time-frequency analysis, see Hoechstetter et al. (2004). The power change percentage was computed relative to the baseline period of $100 \mathrm{~ms}$ before cue onset, without any transformation before statistical analyses (e.g., $\log 10)$, because the percentage power change rather than power spectral density was analyzed. The frequency sampling range was $4-100 \mathrm{~Hz}$, which included the theta $(4-8$ $\mathrm{Hz})$, alpha $(8-12 \mathrm{~Hz})$, beta $(12-30 \mathrm{~Hz})$, low gamma $(30-80 \mathrm{~Hz})$, and a portion of the high gamma $(80-100 \mathrm{~Hz})$ bands. Studies have suggested that high $(80-150 \mathrm{~Hz})$ and low gamma band activity are functionally distinct (Edwards et al., 2005; Canolty et al., 2006).

Diagrams of power spectrum percentage change compared with baseline as a function of time and frequency from each participant were further smoothed with a two-dimensional Gaussian kernel with an SD of $6 \mathrm{~Hz} / 75 \mathrm{~ms}$, and group data analyses for source-localized power spectrum change were conducted. The average difference between ready cue and relax cue conditions was plotted over all dipoles, and the $t$ values for the difference calculated for all time-frequency data points were plotted as a color map. A Monte Carlo simulation of the current study provided that, assuming an individual pixel type I error of $p<0.01$, 20 contiguous original pixels were needed to correct for multiple comparisons. For example, for $5 \times 4$ pixels in the time-frequency $t$ map, converted to the area, the threshold for a cluster extent was 10 $\mathrm{Hz} \times 100 \mathrm{~ms}$ for $\left|t_{(15)}\right|>2.95$.

Source models for the target-locked and response-locked ERP were constructed using the target-locked and response-locked grand averages with dipole locations based on the fMRI regions activated in the response conflict effect. Power spectrum analyses were performed for the no-cuetarget-congruent, no-cue-target-incongruent, cue-target-congruent, and cue-target-incongruent conditions in each participant. Power spectrum change compared with baseline as a function of time for the cue effect on target (cued vs uncued target), conflict effect (congruent vs incongruent flankers), and their interaction were tested.

In summary, we isolated neural activity related to response anticipation using a cued imperative target paradigm designed to elicit the CNV by contrasting a "ready" versus a "relax" cue condition. In addition, we examined neural activity related to response conflict processing by contrasting activation during the subsequent response to a target surrounded by incongruent versus congruent flankers. Furthermore, we compared both the behavioral and neural conflict effects during the response to cued versus uncued targets to examine the interactivity of response anticipation and response conflict.

\section{Results}

\section{Behavioral results}

Figure $2 \mathrm{~A}$ illustrates that RTs were significantly shorter for cued than uncued target responses collected during ERP and 
fMRI testing sessions (ERP, 562 vs $631 \mathrm{~ms}$, $F_{(1,15)}=13.87, p<0.01 ; \mathrm{fMRI}, 674$ vs 751 $\left.\mathrm{ms}, F_{(1,19)}=37.57, p<0.01\right)$, and for congruent versus incongruent targets (ERP, 591 vs $646 \mathrm{~ms}, F_{(1,15)}=49.33, p<0.01$; fMRI, 682 vs $743 \mathrm{~ms}, F_{(1,19)}=41.98, p<$ $0.01)$. The interaction between cue and conflict for RTs of responses collected during fMRI scanning was not significant $(F<1)$, although a nonsignificant trend toward an interaction was observed for RTs during ERP testing $\left(F_{(1,15)}=3.76 ; p=\right.$ $0.07)$. Figure $2 B$ shows that there was no significant cue effect on accuracy during ERP testing (94 vs $92 \% ; F_{(1,15)}=1.94$; $p>.05)$, but accuracy was greater for cued than uncued targets during fMRI testing $\left(88\right.$ vs $\left.82 \% ; F_{(1,19)}=9.46 ; p<0.01\right)$. Accuracy was significantly greater for congruent than incongruent targets during $\operatorname{ERP}\left(96\right.$ vs $\left.90 \% ; F_{(1,15)}=5.14 ; p<0.05\right)$ and $\mathrm{fMRI}\left(88\right.$ vs $82 \% ; F_{(1,19)}=16.35 ; p<$ $0.01)$ testing. The interaction between cue and conflict on accuracy during both ERP and $\mathrm{fMRI}$ testing was not significant (ERP, $F<1$; fMRI, $\left.F_{(1,19)}=2.78, p>0.05\right)$.

\section{Cue-related brain activity}

ERP results

Figure $3 A$ shows the ERP waveform calculated from the average of channel E6 and the six surrounding channels located at the peak of the topography illustrated in Figure $3 B$. The CNV peaked at $700 \mathrm{~ms}$ over the interval from 500 to $1400 \mathrm{~ms}$ after the presentation of a ready cue. Because we used a short S1-S2 interstimulus interval (ISI) and a $0.1-100 \mathrm{~Hz}$ bandpass filter, the early and late components of the CNV could not be dissociated. A paired $t$ test showed that the mean amplitude differ-

ence between the ready and relax cues over 600-1000 ms was significant for the multiple averaged midline electrodes $\left(t_{(15)}=\right.$ $2.76 ; p<0.01$, one-tailed). Figure $3 B$ shows the topography of the voltage difference between the ready and relax cues at $699 \mathrm{~ms}$ after cue onset, with the negative voltage distributed over the dorsofrontal surface of the skull. In addition, a lateralized posterior positivity was observed.

\section{fMRI results}

Table 1 and Figure 4, $A$ and $B$, illustrate that fMRI contrasts of the ready minus relax cue conditions isolated a distributed thalamocortico-striatal network, including several right-lateralized regions previously associated with response anticipation and preparation functions [i.e., caudate and putamen, midbrain, thalamus, pre-supplementary motor area (pre-SMA)], as well as several regions that have been implicated in executive control (i.e., anterior cingulate, middle frontal gyrus, superior frontal gyrus, and parietal cortex).

\section{ERP and power spectrum analysis results}

Nine dipoles were modeled with the coordinates converted from Table 1. The center panel of Figure 5 illustrates the localization of these dipoles. The residual variance after fitting the model to the cue-locked grand average ERP data was 33\%.

Figure 5 also shows the differences in power change of $4-100$ $\mathrm{Hz}$ frequency bands between the ready and relax cue conditions as a function of time and frequency. The comparison of the power spectrum change relative to the baseline period in the ready versus relax cue conditions revealed that response anticipation was associated with greater gamma power $(30-100 \mathrm{~Hz})$ sustained over the cue-target interval in frontal regions, particularly the right superior frontal gyrus, as well as in the superior parietal lobule. In conjunction with the increase in gamma band power, there was a decrease in power in the theta $(4-8 \mathrm{~Hz})$, alpha $(8-12 \mathrm{~Hz})$, and beta $(12-30 \mathrm{~Hz})$ bands in most regions, particularly the right superior occipital gyrus. In addition, there was a decrease in gamma band power in the ACC source. The gamma increase in the left precentral gyrus appeared greater than in right precentral gyrus.

Correlation analysis results

Figure 6 shows that, for the ready cue condition, the mean amplitude of the CNV over the interval of 600-1000 ms was correlated with mean RTs $(r=0.53 ; p<0.05 ; \mathrm{df}=14$; two-tailed). We 

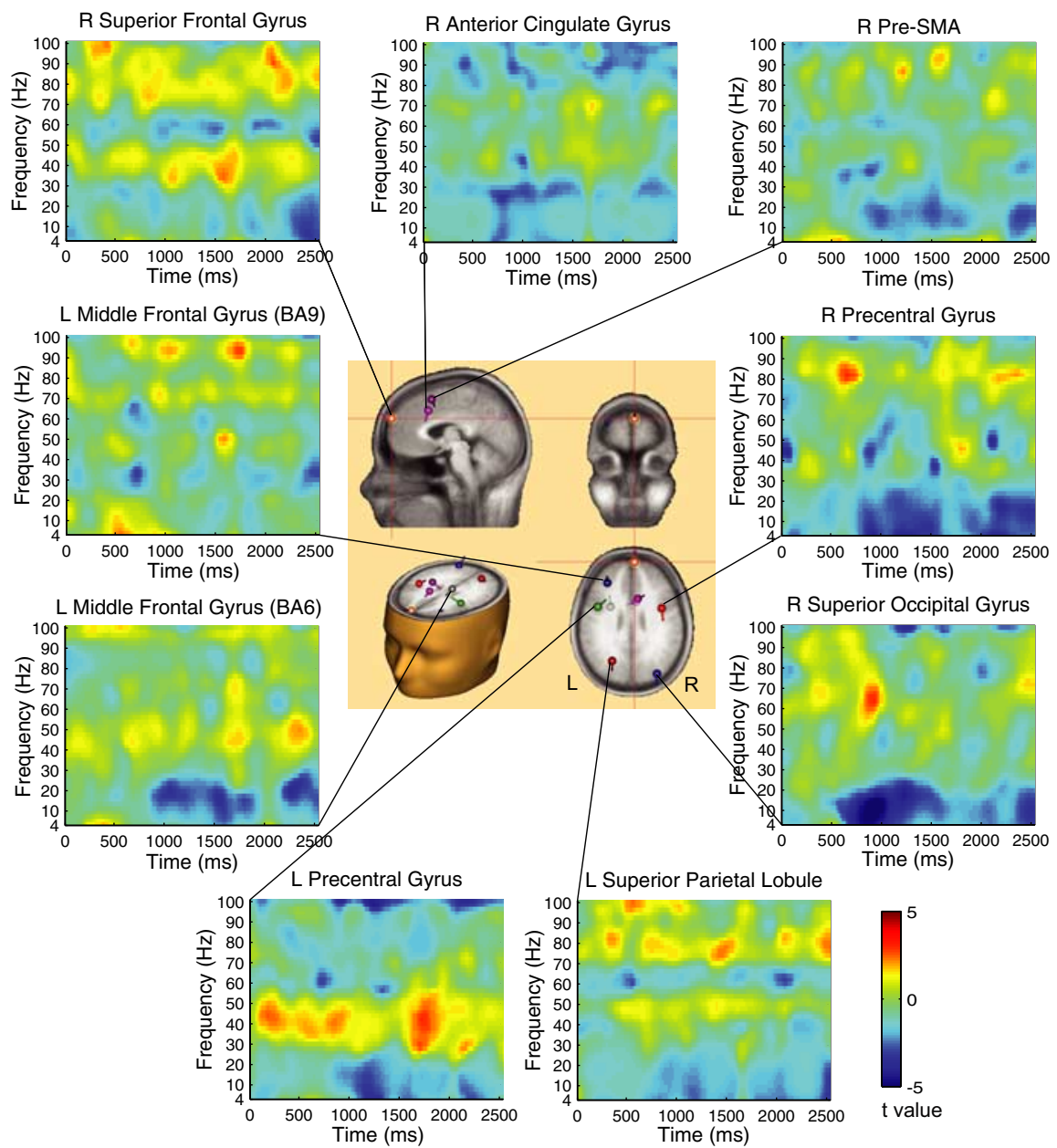

R Superior Occipital Gyrus

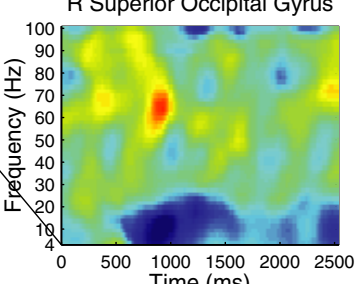

Figure 5. Power change difference diagrams for the ready minus relax cue contrast as a function of time-frequency and the dipoles of ERP data. The center panel shows the dipole locations. The small balls and bars represent the locations and orientations of the dipoles, respectively. The right superior frontal gyrus showed greater gamma $(>30 \mathrm{~Hz})$ power maintained over the cue-target interval, whereas the right superior occipital gyrus showed power decrease in theta $(4-8 \mathrm{~Hz})$, alpha $(8-12 \mathrm{~Hz})$, and beta $(12-30 \mathrm{~Hz})$ bands. The cue onset is at $0 \mathrm{~ms}$, and the target onset is at $2500 \mathrm{~ms}$.

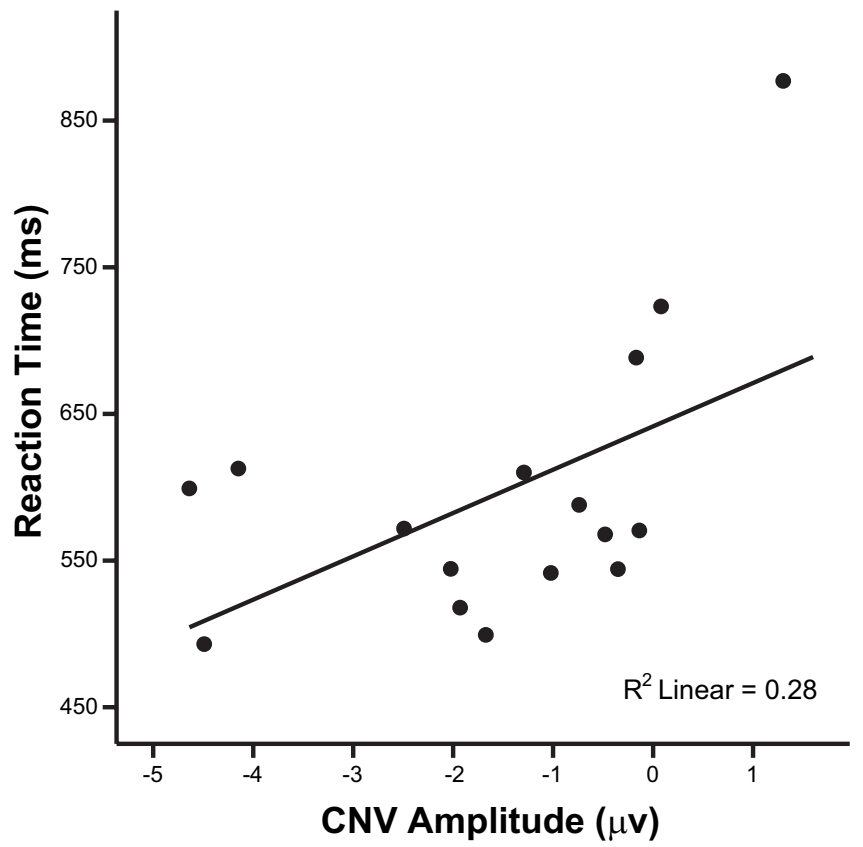

Figure 6. Scattergram showing the relationship between mean CNV amplitudes and mean RTs in the ready cue condition across participants. estimated the linear, quadratic, and cubic curve fitting and found that the curvilinear solutions best fit the data $\left(R^{2}=0.28\right.$, $F_{(14)}=5.34, p<0.05 ; R^{2}=0.71, F_{(13)}=$ $16.11, p<0.001$; and $R^{2}=0.77, F_{(12)}=$ $13.17, p<0.001$, respectively). The positive correlation indicated that participants with more negative CNV amplitudes had shorter RTs. However, in the presence of the CNV (i.e., when the amplitude is negative), there is a plateau effect on the relationship between CNV amplitude and RTs.

The correlations between CNV amplitude and gamma band power change in the right superior frontal gyrus $(r=0.41)$, correlations between RTs and gamma band power change in the right superior frontal gyrus $(r=0.38)$, as well as correlations between RTs and alpha band power change in the right superior occipital gyrus $(r=-0.15)$, were not significant. There was no significant correlation between RTs and BOLD signal change in the right superior frontal gyrus $(r=0.10)$. However, the correlation between RT and BOLD signal change in the right superior occipital gyrus was -0.44 ( $p=0.08$, twotailed), indicating a trend that shorter RTs were associated with greater right superior occipital gyrus activation.

\section{Conflict-related brain activity}

The target-locked ERP calculated from the mean of channel E6 and the six surrounding channels had a positive peak at $200 \mathrm{~ms}$ (P1), a negative peak at $300 \mathrm{~ms}(\mathrm{~N} 2)$, and another positive peak at $450 \mathrm{~ms}(\mathrm{P} 3)$ after target presentation. ANOVA showed a significant main effect of cue on the latency of the P1 component $\left(F_{(1,11)}=10.37 ; p<0.01\right)$, demonstrating a shorter latency for the cued target response (201 vs $215 \mathrm{~ms}$ ). There were no significant main effects of cue or target, nor any interaction between these factors, for the peak amplitude and latency of the other components. Table 2 and Figure 7 show that the "conflict effect" contrast of incongruent versus congruent target conditions in fMRI revealed activation of several regions of the executive control network, including the left and right middle frontal gyrus, left anterior cingulate gyrus, and right medial frontal gyrus, as well as other regions, including the left superior parietal lobule, right precuneus, and right paracentral lobule. For the conflict contrast, the residual variance after fitting the dipole models to the grand averages of target-locked and responselocked ERP data were 41.6 and $45.0 \%$. Possibly related to the high variance unexplained by the models, no spectral power change effects were observed for the contrast between incongruent and congruent conditions.

\section{Effects of cue condition on target response}

Table 3 shows the contrast between uncued versus cued targetrelated BOLD signal change. Greater activation was observed for uncued targets in regions implicated in executive control, 
including the left middle frontal gyrus, right and left anterior cingulate gyrus, and left superior frontal gyrus. However, there was no significant interaction between the cue condition (uncued vs cued) and the target condition (incongruent vs congruent). These results indicated that, although the cue reduced the overall magnitude of activation of the executive control network during the target response, cue condition did not affect the magnitude of the conflict effect, that is, the difference between the BOLD response to incongruent versus congruent targets. Figure 8 illustrates the ACC activation during responses to targets with incongruent and congruent flankers under uncued and cued conditions. The main effect of cue condition on target-related activation was significant, with greater activation for uncued targets. The conflict effects were significant for both cued and uncued targets, but did not differ between uncued and cued conditions. No spectral power change effects were observed for the interaction between cue conditions and conflict conditions.

\section{Consistent activation in response anticipation and response conflict processes}

Table 4 lists the locations of maximum activity for the computed conjunction. Regions of overlap between response anticipation and response conflict processes can be seen in Figure 9. Consistent activation was observed in the bilateral middle frontal gyrus, ACC, superior parietal lobule, and precentral gyrus, as well as in the right superior occipital gyrus, right caudate nucleus and right thalamus.

\section{Discussion}

Top-down processes of response anticipation

Response anticipation generated a CNV, which was associated with faster responses, consistent with studies showing the involvement of the CNV in cued target anticipation and motor preparation (Rosahl and Knight, 1995; Ulrich et al., 1998; Leuthold and Jentzsch, 2001). This result suggests that response anticipation facilitates response preparation and execution. In addition, our results demonstrated an association between generation of the $\mathrm{CNV}$ and activation of a thalamo-cortico-striatal network, consistent with a simultaneous EEG/fMRI study showing that trial-by-trial CNV amplitude is correlated with BOLD activation in the ACC, SMA, and thalamus (Nagai et al., 2004), and other studies showing that the CNV is generated by a thalamo-cortico-striatal circuit, including the cingulate gyrus and caudate nucleus (Rebert, 1972; McCallum and Cummins, 1973; Rebert et al., 1986; Ikeda et al., 1997). It has been suggested that response anticipation increases cortical excitabil-
Table 2. BOLD signal differences between incongruent and congruent target conditions

\begin{tabular}{|c|c|c|c|c|c|c|c|}
\hline \multirow[b]{2}{*}{ Region } & \multirow[b]{2}{*}{ BA } & \multicolumn{3}{|c|}{ MNI coordinates } & \multirow[b]{2}{*}{ Voxel } & \multirow[b]{2}{*}{ Z } & \multirow[b]{2}{*}{$p$} \\
\hline & & $x$ & $y$ & $z$ & & & \\
\hline L middle frontal gyrus & 9 & -52 & 24 & 26 & 532 & 4.14 & 0.001 \\
\hline R middle frontal gyrus & 8 & 22 & 34 & 42 & 1331 & 3.76 & 0.001 \\
\hline L anterior cingulate gyrus & 32 & -8 & 24 & 38 & 767 & 3.75 & 0.001 \\
\hline L superior parietal lobule & 7 & -38 & -72 & 44 & 354 & 3.64 & 0.001 \\
\hline L middle frontal gyrus & 9 & -32 & 42 & 32 & 332 & 3.46 & 0.001 \\
\hline R precuneus & 7 & 8 & -44 & 50 & 287 & 2.95 & 0.002 \\
\hline R medial frontal gyrus & 6 & 10 & -16 & 48 & & 2.85 & 0.002 \\
\hline R paracentral lobule & 5 & 6 & -30 & 48 & & 2.45 & 0.007 \\
\hline
\end{tabular}
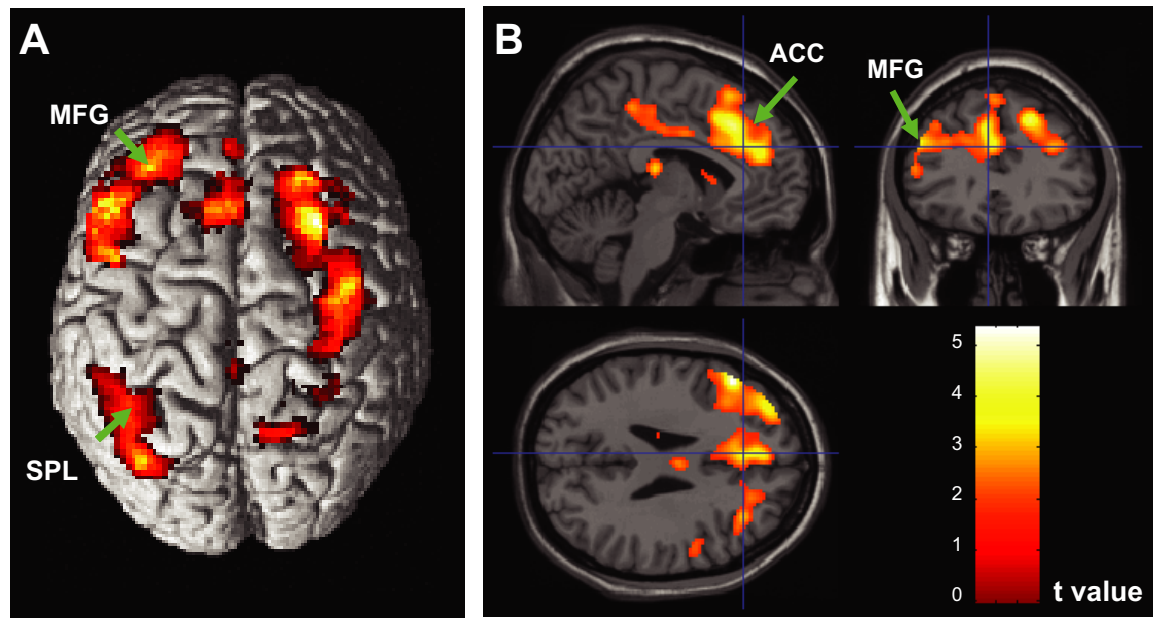

Figure 7. Brain activation associated with response conflict (incongruent vs congruent) shown on the surface $(\boldsymbol{A})$ and cross views (B). MFG, Middle frontal gyrus; SPL, superior parietal lobule.

Table 3. BOLD signal differences between uncued and cued target conditions

\begin{tabular}{|c|c|c|c|c|c|c|c|}
\hline \multirow[b]{2}{*}{ Region } & \multirow[b]{2}{*}{ BA } & & \multirow[b]{2}{*}{ Voxel } & \multirow[b]{2}{*}{ Z } & \multirow[b]{2}{*}{$p$} \\
\hline & & $x$ & $y$ & $z$ & & & \\
\hline L precentral gyrus & 6 & -40 & 2 & 32 & 3545 & 4.68 & 0.001 \\
\hline L inferior frontal gyrus & 46 & -40 & 42 & 4 & & 4.56 & 0.001 \\
\hline L middle frontal gyrus & 9 & -32 & 36 & 30 & & 4.45 & 0.001 \\
\hline L superior occipital gyrus & 19 & -28 & -86 & 28 & 2734 & 4.44 & 0.001 \\
\hline L lingual gyrus & 37 & -22 & -44 & -2 & & 3.52 & 0.001 \\
\hline R superior occipital gyrus & 19 & 30 & -78 & 24 & & 3.52 & 0.001 \\
\hline R anterior cingulate gyrus & 32 & 8 & 24 & 40 & 779 & 4.22 & 0.001 \\
\hline L anterior cingulate gyrus & 32 & -8 & 18 & 38 & & 2.90 & 0.002 \\
\hline R precentral gyrus & 6 & 42 & 6 & 34 & 853 & 4.15 & 0.001 \\
\hline R thalamus (pulvinar) & & 14 & -24 & 8 & 110 & 3.58 & 0.001 \\
\hline R fusiform gyrus & 19 & 26 & -60 & -2 & 118 & 3.23 & 0.001 \\
\hline L superior frontal gyrus & 6 & -22 & 14 & 52 & 122 & 3.12 & 0.001 \\
\hline L superior parietal lobule & 7 & -30 & -56 & 48 & 132 & 3.00 & 0.001 \\
\hline R temporoparietal junction & 22 & 56 & -42 & 16 & 80 & 2.86 & 0.002 \\
\hline
\end{tabular}

L, Left; R, right; BA, Brodmann area.

ity in task-relevant regions through generation of the CNV, priming these regions for improved target processing. ERP studies have found that trial-by-trial frontocentral CNV amplitude predicts response accuracy and is correlated with extrastriate activation in a flanker letter discrimination task (Padilla et al., 2006), and that the amplitude of a negative ERP waveform elicited by a cue predicts later recollection of a subsequent target word (Otten et al., 2006).

Our fMRI analysis enabled specific spatial localization of the regions activated in the cue effects. Contrasting the BOLD signal after a ready versus relax cue demonstrated that response antici- 
pation was associated with activation of a thalamo-corticostriatal network, including the middle frontal gyrus, superior frontal gyrus, superior parietal lobule, pre-SMA, ACC, thalamus, and basal ganglia. The PFC has bidirectional connections with multiple brain regions, including sensory, motor, and subcortical structures, placing it in an ideal anatomical position to monitor and control numerous cognitive processes (Miller et al., 2002). The PFC has been implicated in top-down control of taskrelevant regions during response anticipation (Fuller and Jahanshahi, 1999; Miller, 2000; Liang et al., 2002; Fassbender et al., 2006), as well as in the active maintenance of task goals and representations (Barcelo et al., 2000; Miller and Cohen, 2001).

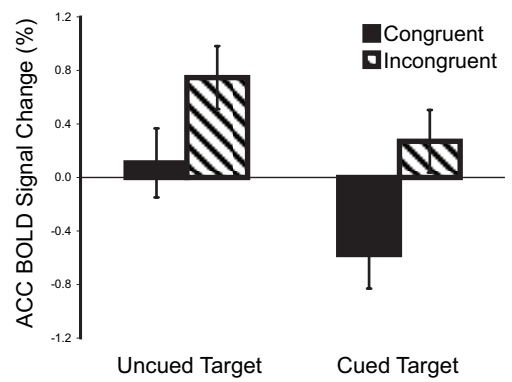

Figure 8. $\quad A C C$ activation under different cue and target conditions. Greater activation was observed during the response to uncued versus cued targets, and to targets with incongruent versus congruent flankers. However, the conflict effects did not differ between these two cue conditions. Error bars represent \pm 1 SEM for each condition.

Table 4. Consistent activation in response anticipation and response conflict processes

\begin{tabular}{|c|c|c|c|c|c|c|c|}
\hline \multirow[b]{2}{*}{ Region } & \multirow[b]{2}{*}{$B A$} & \multicolumn{3}{|c|}{ MNI coordinates } & \multirow[b]{2}{*}{ Voxel } & \multirow[b]{2}{*}{$Z$} & \multirow[b]{2}{*}{$p$} \\
\hline & & $x$ & $y$ & $z$ & & & \\
\hline L precentral gyrus & 6 & -40 & 0 & 36 & 1074 & 4.74 & 0.001 \\
\hline R superior occipital gyrus & 19 & 34 & -78 & 30 & 211 & 4.64 & 0.001 \\
\hline R precentral gyrus & 6 & 42 & 2 & 44 & 680 & 4.33 & 0.001 \\
\hline$R$ caudate nucleus & & 4 & 8 & 6 & 500 & 3.97 & 0.001 \\
\hline L anterior cingulate gyrus $^{a}$ & 32 & -4 & 14 & 48 & 629 & 3.93 & 0.001 \\
\hline L superior parietal lobule & 7 & -30 & -56 & 52 & 1241 & 3.68 & 0.001 \\
\hline L middle frontal gyrus & 9 & -32 & 44 & 22 & 163 & 3.49 & 0.001 \\
\hline R thalamus & & 6 & -26 & 2 & 120 & 3.37 & 0.001 \\
\hline R superior parietal lobule & 7 & 22 & -48 & 52 & 200 & 3.13 & 0.001 \\
\hline R middle frontal gyrus & 9 & 20 & 46 & 24 & 87 & 3.00 & 0.001 \\
\hline
\end{tabular}

$L$, Left; $R$, right; $B A$, Brodmann area.

${ }^{a}$ Extends to pre-SMA and the second local maxima is in right anterior cingulate gyrus.
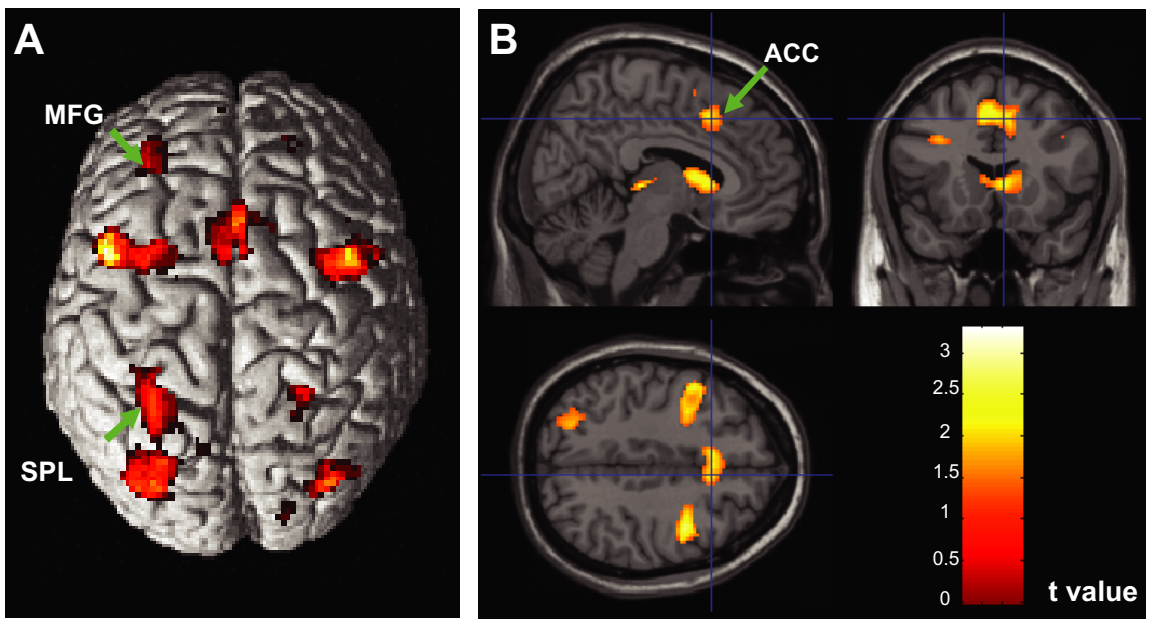

Figure 9. $\quad \boldsymbol{A}, \boldsymbol{B}$, Regions showing consistent activation in response anticipation and response conflict processes shown on the surface $(\boldsymbol{A})$ and cross views $(\boldsymbol{B})$. MFG, Middle frontal gyrus; SPL, superior parietal lobule.
Similarly, studies have suggested that the ACC, superior frontal cortex, and cortical regions along the intraparietal sulcus are involved in cued task-set implementation and in holding information on-line during response anticipation (Petit et al., 1998; Quintana et al., 2004; Dosenbach et al., 2006). In addition, prefrontal and parietal regions are involved in sustaining attention during response anticipation (Desimone, 1996; Hopfinger et al., 2000). The ACC, along with the PFC (Frith et al., 1991; Cohen et al., 1999) and basal ganglia (Pasupathy and Miller, 2005), which are interconnected in corticobasal ganglionic loops (Middleton and Strick, 2002), have been implicated in volitional action, consistent with their activation during the period after a ready cue as opposed to a relax cue. Furthermore, studies have implicated the pre-SMA (Lee et al., 1999), basal ganglia (Alexander and Crutcher, 1990), thalamus (Paradiso et al., 2004), middle frontal gyrus (Lang et al., 1988), and anterior cingulate (Deiber et al., 1999) in motor planning.

Power spectrum analysis of the pretarget period provided additional insight into the nature of preparatory processing within various frontal and posterior brain regions during response anticipation. The comparison of power spectrum change in the ready versus the relax cue conditions revealed that response anticipation was associated with greater gamma power sustained over the cue-target interval, in conjunction with decreased power in the theta, alpha, and beta bands. This result suggests that response anticipation is subserved by increased activity in these regions, because greater gamma band power and reduced alpha band power have both been associated with increased neuronal activity (Klimesch et al., 1999; Pfurtscheller and Lopes da Silva, 1999; Steriade, 1999; Salinas and Sejnowski, 2001). Reduced alpha band power is caused by event-related desynchronization (ERD) of the alpha band, which may reflect the flow of information from thalamocortical networks to the primary somatosensory cortex, facilitated by thalamic reticular cells (Brunia, 1999). Activity in this network has been suggested to contribute to the generation of the CNV (Birbaumer et al., 1990). A recent study (Mukamel et al., 2005) has demonstrated a negative correlation between BOLD signal and local field potentials in the auditory cortex at frequencies of 5-15 Hz, which includes the alpha range, but a positive correlation at frequencies in the gamma range of $40-130 \mathrm{~Hz}$, supporting the potential linkage between $\mathrm{fMRI}$ activation and spectral power change.

Our finding of increased gamma band activity and decreased alpha band activity in regions associated with attention, sensory processing, and motor preparation supports the contention that the PFC exerts top-down control of task-relevant brain regions in response to a ready cue. The PFC has been proposed to facilitate anticipatory processes through the synchronization of local field potential oscillations (Engel et al., 2001; Liang et al., 2002). Studies have implicated gamma-frequency oscillations in top-down attentional pro- 
cessing (Tiitinen et al., 1993; Debener et al., 2003; Tallon-Baudry et al., 2005), and have demonstrated increased gamma power and alpha ERD in the sensorimotor cortex during the expectancy of relevant or informative stimuli (Klimesch et al., 1998; Bastiaansen et al., 2001; Bastiaansen and Brunia, 2001; Filipovic et al., 2001) and during movement preparation and execution (Sanes and Donoghue, 1993; Toro et al., 1994; Andrew and Pfurtscheller, 1996; Leocani et al., 1997; Pfurtscheller and Lopes da Silva, 1999; Lee, 2003; Bender et al., 2005; Deiber et al., 2005; Gonzalez Andino et al., 2005). Furthermore, it has been shown that gamma-frequency oscillations very early in the period between a warning cue and visual stimulus are correlated with shorter reaction times to the stimulus on a trial-by-trial basis (Gonzalez Andino et al., 2005).

\section{Executive control of response conflict}

Response conflict was associated with increased activity in the ACC and dorsolateral PFC, consistent with studies indicating that these areas are part of an executive control network that monitors both conflict and behavioral responses (Turken and Swick, 1999; Botvinick et al., 2001; Fan et al., 2005). Several regions were activated during both response anticipation and conflict processing, suggesting that the conflict processes share several regions with the top-down processes of response anticipation. These regions included the left middle frontal gyrus (BA9) and left superior parietal lobule (BA7), which are integral to the dorsal frontoparietal networks subserving the top-down control of visual attention (Corbetta and Shulman, 2002), as well as the ACC, which, together with the PFC, has been previously implicated in both response anticipation and conflict monitoring and resolution (Petit et al., 1998; Liang et al., 2002; Quintana et al., 2004). The role of the PFC in the top-down control of taskrelevant regions and the role of the ACC in cued task-set implementation and error monitoring (Dosenbach et al., 2006) may account for their joint involvement in both anticipatory and conflict processes. In contrast, several regions of activation were unique to response anticipation, such as the superior frontal gyrus (area 10). Overall, these results suggest that the dorsal frontoparietal networks for the top-down control of visual attention, as well as the ACC, may be involved in both response anticipation and response conflict processing.

\section{Modulation of target response by response anticipation}

Reaction times were shorter and accuracy was greater for responses to cued versus uncued targets. In addition, reaction times were longer and accuracy was reduced for responses to incongruent versus congruent targets. Although main effects of cue and conflict were found on behavioral performance and fMRI activation, no significant interaction between the cue and conflict effects was found. However, several brain regions implicated in executive control, particularly the ACC and PFC, showed a greater response to uncued than cued targets. The lateral PFC is crucial to the inhibitory control of sensory processing (Chao and Knight, 1998) and interacts with the ACC in monitoring behavior to assess the need for the implementation of executive control (Gehring and Knight, 2000). In the present study, because the conflict effect was unchanged between cued and uncued conditions, the greater activation in regions of the dorsal frontoparietal network and the ACC suggests that top-down control is implemented during target processing to a greater extent when this control is not recruited in advance because of an absence of preparation.

Together, the current results provide information about the brain networks subserving response anticipation and response conflict processing, indicating that these networks are comprised of some distinct as well as some common brain regions. The effects of response anticipation and response conflict are additive, with regions associated with response conflict showing greater activation during a response to an unanticipated target. However, the absence of an interaction between the cue and conflict effects suggests that these networks operate to some degree independently to support the flexible task-dependent recruitment of regions such as the PFC, ACC, and parietal lobule during the implementation of executive control.

\section{References}

Alexander GE, Crutcher MD (1990) Preparation for movement: neural representations of intended direction in three motor areas of the monkey. J Neurophysiol 64:133-150.

Andrew C, Pfurtscheller G (1996) Event-related coherence as a tool for studying dynamic interaction of brain regions. Electroencephalogr Clin Neurophysiol 98:144-148.

Badler JB, Heinen SJ (2006) Anticipatory movement timing using prediction and external cues. J Neurosci 26:4519-4525.

Barcelo F, Suwazono S, Knight RT (2000) Prefrontal modulation of visual processing in humans. Nat Neurosci 3:399-403.

Bastiaansen MC, Brunia CH (2001) Anticipatory attention: an eventrelated desynchronization approach. Int J Psychophysiol 43:91-107.

Bastiaansen MC, Bocker KB, Brunia CH, de Munck JC, Spekreijse H (2001) Event-related desynchronization during anticipatory attention for an upcoming stimulus: a comparative EEG/MEG study. Clin Neurophysiol 112:393-403.

Bender S, Weisbrod M, Bornfleth H, Resch F, Oelkers-Ax R (2005) How do children prepare to react? Imaging maturation of motor preparation and stimulus anticipation by late contingent negative variation. NeuroImage 27:737-752.

Bertelson P (1967) The time course of preparation. Q J Exp Psychol 19:272-279.

Birbaumer N, Elbert T, Canavan AG, Rockstroh B (1990) Slow potentials of the cerebral cortex and behavior. Physiol Rev 70:1-41.

Botvinick MM, Braver TS, Barch DM, Carter CS, Cohen JD (2001) Conflict monitoring and cognitive control. Psychol Rev 108:624-652.

Brunia CH (1999) Neural aspects of anticipatory behavior. Acta Psychol (Amst) 101:213-242.

Brunia CH, van Boxtel GJ (2001) Wait and see. Int J Psychophysiol 43:59-75.

Bush G, Luu P, Posner MI (2000) Cognitive and emotional influences in anterior cingulate cortex. Trends Cogn Sci 4:215-222.

Canolty RT, Edwards E, Dalal SS, Soltani M, Nagarajan SS, Kirsch HE, Berger MS, Barbaro NM, Knight RT (2006) High gamma power is phaselocked to theta oscillations in human neocortex. Science 313:1626-1628.

Chao LL, Knight RT (1998) Contribution of human prefrontal cortex to delay performance. J Cogn Neurosci 10:167-177.

Cohen RA, Kaplan RF, Zuffante P, Moser DJ, Jenkins MA, Salloway S, Wilkinson H (1999) Alteration of intention and self-initiated action associated with bilateral anterior cingulotomy. J Neuropsychiatry Clin Neurosci 11:444-453.

Corbetta M, Shulman GL (2002) Control of goal-directed and stimulusdriven attention in the brain. Nat Rev Neurosci 3:201-215.

Crottaz-Herbette S, Menon V (2006) Where and when the anterior cingulate cortex modulates attentional response: combined fMRI and ERP evidence. J Cogn Neurosci 18:766-780.

Dagher A, Owen AM, Boecker H, Brooks DJ (1999) Mapping the network for planning: a correlational PET activation study with the Tower of London task. Brain 122:1973-1987.

Debener S, Herrmann CS, Kranczioch C, Gembris D, Engel AK (2003) Topdown attentional processing enhances auditory evoked gamma band activity. NeuroReport 14:683-686.

Deiber MP, Honda M, Ibanez V, Sadato N, Hallett M (1999) Mesial motor areas in self-initiated versus externally triggered movements examined with fMRI: effect of movement type and rate. J Neurophysiol 81:3065-3077.

Deiber MP, Ibanez V, Caldara R, Andrey C, Hauert CA (2005) Program- 
ming effectors and coordination in bimanual in-phase mirror finger movements. Brain Res Cogn Brain Res 23:374-386.

Desimone R (1996) Neural mechanisms for visual memory and their role in attention. Proc Natl Acad Sci USA 93:13494-13499.

Dosenbach NU, Visscher KM, Palmer ED, Miezin FM, Wenger KK, Kang HC, Burgund ED, Grimes AL, Schlaggar BL, Petersen SE (2006) A core system for the implementation of task sets. Neuron 50:799-812.

Durstewitz D (2004) Neural representation of interval time. NeuroReport 15:745-749.

Edwards E, Soltani M, Deouell LY, Berger MS, Knight RT (2005) High gamma activity in response to deviant auditory stimuli recorded directly from human cortex. J Neurophysiol 94:4269-4280.

Engel AK, Fries P, Singer W (2001) Dynamic predictions: oscillations and synchrony in top-down processing. Nat Rev Neurosci 2:704-716.

Fan J, McCandliss BD, Sommer T, Raz A, Posner MI (2002) Testing the efficiency and independence of attentional networks. J Cogn Neurosci 14:340-347.

Fan J, Flombaum JI, McCandliss BD, Thomas KM, Posner MI (2003) Cognitive and brain consequences of conflict. NeuroImage 18:42-57.

Fan J, McCandliss BD, Fossella J, Flombaum JI, Posner MI (2005) The activation of attentional networks. NeuroImage 26:471-479.

Fassbender C, Foxe JJ, Garavan H (2006) Mapping the functional anatomy of task preparation: priming task-appropriate brain networks. Hum Brain Mapp 27:819-827.

Filipovic SR, Jahanshahi M, Rothwell JC (2001) Uncoupling of contingent negative variation and alpha band event-related desynchronization in a go/no-go task. Clin Neurophysiol 112:1307-1315.

Foxe JJ, Simpson GV, Ahlfors SP, Saron CD (2005) Biasing the brain's attentional set: I. cue driven deployments of intersensory selective attention. Exp Brain Res 166:370-392.

Friston KJ, Fletcher P, Josephs O, Holmes A, Rugg MD, Turner R (1998) Event-related fMRI: characterizing differential responses. NeuroImage $7: 30-40$.

Friston KJ, Penny WD, Glaser DE (2005) Conjunction revisited. NeuroImage 25:661-667.

Frith CD, Friston K, Liddle PF, Frackowiak RS (1991) Willed action and the prefrontal cortex in man: a study with PET. Proc Biol Sci 244:241-246.

Fuller R, Jahanshahi M (1999) Impairment of willed actions and use of advance information for movement preparation in schizophrenia. J Neurol Neurosurg Psychiatry 66:502-509.

Fuster JM (1990) Behavioral electrophysiology of the prefrontal cortex of the primate. Prog Brain Res 85:313-323.

Gehring WJ, Knight RT (2000) Prefrontal-cingulate interactions in action monitoring. Nat Neurosci 3:516-520.

Glover GH, Thomason ME (2004) Improved combination of spiral-in/out images for BOLD fMRI. Magn Reson Med 51:863-868.

Gonzalez Andino SL, Michel CM, Thut G, Landis T, Grave de Peralta R (2005) Prediction of response speed by anticipatory high-frequency (gamma band) oscillations in the human brain. Hum Brain Mapp 24:50-58.

Gruber O, Goschke T (2004) Executive control emerging from dynamic interactions between brain systems mediating language, working memory and attentional processes. Acta Psychol (Amst) 115:105-121.

Hoechstetter K, Bornfleth H, Weckesser D, Ille N, Berg P, Scherg M (2004) BESA source coherence: a new method to study cortical oscillatory coupling. Brain Topogr 16:233-238.

Hopfinger JB, Buonocore MH, Mangun GR (2000) The neural mechanisms of top-down attentional control. Nat Neurosci 3:284-291.

Ikeda A, Shibasaki H, Kaji R, Terada K, Nagamine T, Honda M, Kimura J (1997) Dissociation between contingent negative variation (CNV) and Bereitschaftspotential (BP) in patients with parkinsonism. Electroencephalogr Clin Neurophysiol 102:142-151.

Isomura Y, Ito Y, Akazawa T, Nambu A, Takada M (2003) Neural coding of "attention for action" and "response selection" in primate anterior cingulate cortex. J Neurosci 23:8002-8012.

Johnstone T, Ores Walsh KS, Greischar LL, Alexander AL, Fox AS, Davidson RJ, Oakes TR (2006) Motion correction and the use of motion covariates in multiple-subject fMRI analysis. Hum Brain Mapp 27:779-788.

Klimesch W, Doppelmayr M, Russegger H, Pachinger T, Schwaiger J (1998) Induced alpha band power changes in the human EEG and attention. Neurosci Lett 244:73-76.

Klimesch W, Doppelmayr M, Schwaiger J, Auinger P, Winkler T (1999)
"Paradoxical" alpha synchronization in a memory task. Brain Res Cogn Brain Res 7:493-501.

Komura Y, Tamura R, Uwano T, Nishijo H, Kaga K, Ono T (2001) Retrospective and prospective coding for predicted reward in the sensory thalamus. Nature 412:546-549.

Lang W, Lang M, Podreka I, Steiner M, Uhl F, Suess E, Muller C, Deecke L (1988) DC-potential shifts and regional cerebral blood flow reveal frontal cortex involvement in human visuomotor learning. Exp Brain Res 71:353-364.

Lee D (2003) Coherent oscillations in neuronal activity of the supplementary motor area during a visuomotor task. J Neurosci 23:6798-6809.

Lee KM, Chang KH, Roh JK (1999) Subregions within the supplementary motor area activated at different stages of movement preparation and execution. NeuroImage 9:117-123.

Leocani L, Toro C, Manganotti P, Zhuang P, Hallett M (1997) Event-related coherence and event-related desynchronization/synchronization in the $10 \mathrm{~Hz}$ and $20 \mathrm{~Hz}$ EEG during self-paced movements. Electroencephalogr Clin Neurophysiol 104:199-206.

Leuthold H, Jentzsch I (2001) Neural correlates of advance movement preparation: a dipole source analysis approach. Brain Res Cogn Brain Res $12: 207-224$.

Liang H, Bressler SL, Ding M, Truccolo WA, Nakamura R (2002) Synchronized activity in prefrontal cortex during anticipation of visuomotor processing. NeuroReport 13:2011-2015.

Macar F, Vidal F (2003) The CNV peak: an index of decision making and temporal memory. Psychophysiology 40:950-954.

MacDonald III AW, Cohen JD, Stenger VA, Carter CS (2000) Dissociating the role of the dorsolateral prefrontal and anterior cingulate cortex in cognitive control. Science 288:1835-1838.

McCallum WC, Cummins B (1973) The effects of brain lesions on the contingent negative variation in neurosurgical patients. Electroencephalogr Clin Neurophysiol 35:449-456.

Middleton FA, Strick PL (2002) Basal-ganglia "projections" to the prefrontal cortex of the primate. Cereb Cortex 12:926-935.

Miller EK (2000) The prefrontal cortex and cognitive control. Nat Rev Neurosci 1:59-65.

Miller EK, Cohen JD (2001) An integrative theory of prefrontal cortex function. Annu Rev Neurosci 24:167-202.

Miller EK, Freedman DJ, Wallis JD (2002) The prefrontal cortex: categories, concepts and cognition. Philos Trans R Soc Lond B Biol Sci 357:1123-1136.

Mukamel R, Gelbard H, Arieli A, Hasson U, Fried I, Malach R (2005) Coupling between neuronal firing, field potentials, and FMRI in human auditory cortex. Science 309:951-954.

Nagai Y, Critchley HD, Featherstone E, Fenwick PB, Trimble MR, Dolan RJ (2004) Brain activity relating to the contingent negative variation: an fMRI investigation. NeuroImage 21:1232-1241.

Otten LJ, Quayle AH, Akram S, Ditewig TA, Rugg MD (2006) Brain activity before an event predicts later recollection. Nat Neurosci 9:489-491.

Padilla ML, Wood RA, Hale LA, Knight RT (2006) Lapses in a prefrontalextrastriate preparatory attention network predict mistakes. J Cogn Neurosci 18:1477-1487.

Papp N, Ktonas P (1977) Critical evaluation of complex demodulation techniques for the quantification of bioelectrical activity. Biomed Sci Instrum 13:135-145.

Paradiso G, Cunic D, Saint-Cyr JA, Hoque T, Lozano AM, Lang AE, Chen R (2004) Involvement of human thalamus in the preparation of self-paced movement. Brain 127:2717-2731.

Pasupathy A, Miller EK (2005) Different time courses of learning-related activity in the prefrontal cortex and striatum. Nature 433:873-876.

Petit L, Courtney SM, Ungerleider LG, Haxby JV (1998) Sustained activity in the medial wall during working memory delays. I Neurosci 18:9429-9437.

Pfeuty M, Ragot R, Pouthas V (2005) Relationship between CNV and timing of an upcoming event. Neurosci Lett 382:106-111.

Pfurtscheller G, Lopes da Silva FH (1999) Event-related EEG/MEG synchronization and desynchronization: basic principles. Clin Neurophysiol 110:1842-1857.

Quintana J, Wong T, Ortiz-Portillo E, Marder SR, Mazziotta JC (2004) Anterior cingulate dysfunction during choice anticipation in schizophrenia. Psychiatry Res 132:117-130.

Rebert CS (1972) Cortical and subcortical slow potentials in the monkey's 
brain during a preparatory interval. Electroencephalogr Clin Neurophysiol 33:389-402.

Rebert CS, Tecce JJ, Marczynski TJ, Pirch JH, Thompson JW (1986) Neural anatomy, chemistry and event-related brain potentials: an approach to understanding the substrates of mind. Electroencephalogr Clin Neurophysiol Suppl 38:343-392.

Rockstroh B, Muller M, Wagner M, Cohen R, Elbert T (1993) "Probing" the nature of the CNV. Electroencephalogr Clin Neurophysiol 87:235-241.

Rosahl SK, Knight RT (1995) Role of prefrontal cortex in generation of the contingent negative variation. Cereb Cortex 5:123-134.

Salinas E, Sejnowski TJ (2001) Correlated neuronal activity and the flow of neural information. Nat Rev Neurosci 2:539-550.

Sanes JN, Donoghue JP (1993) Oscillations in local field potentials of the primate motor cortex during voluntary movement. Proc Natl Acad Sci USA 90:4470-4474.

Slotnick SD, Schacter DL (2004) A sensory signature that distinguishes true from false memories. Nat Neurosci 7:664-672.

Steriade M (1999) Cellular substrates of brain rhythms. In: Electroencephalography: basic principles, clinical applications, and related fields, Ed 4 (Niedermeyer E, Lopes da Silva F, eds), pp 28-75. Baltimore: Williams and Wilkins.
Talairach J, Tournoux P (1988) Co-planar stereotaxic atlas of the human brain. New York: Theime.

Tallon-Baudry C, Bertrand O, Henaff MA, Isnard J, Fischer C (2005) Attention modulates gamma-band oscillations differently in the human lateral occipital cortex and fusiform gyrus. Cereb Cortex 15:654-662.

Tecce JJ (1972) Contingent negative variation (CNV) and psychological processes in man. Psychol Bull 77:73-108.

Tiitinen H, Sinkkonen J, Reinikainen K, Alho K, Lavikainen J, Naatanen R (1993) Selective attention enhances the auditory $40-\mathrm{Hz}$ transient response in humans. Nature 364:59-60.

Toro C, Deuschl G, Thatcher R, Sato S, Kufta C, Hallett M (1994) Eventrelated desynchronization and movement-related cortical potentials on the ECoG and EEG. Electroencephalogr Clin Neurophysiol 93:380-389.

Tucker DM (1993) Spatial sampling of head electrical fields: the geodesic sensor net. Electroencephalogr Clin Neurophysiol 87:154-163.

Turken AU, Swick D (1999) Response selection in the human anterior cingulate cortex. Nat Neurosci 2:920-924.

Ulrich R, Leuthold H, Sommer W (1998) Motor programming of response force and movement direction. Psychophysiology 35:721-728.

Walter WG, Cooper R, Aldridge VJ, McCallum WC, Winter AL (1964) Contingent negative variation: An electric sign of sensorimotor association and expectancy in the human brain. Nature 203:380-384. 